\title{
Consumer Behavior in Purchase of Mobile Phone in Urban City of Karachi
}

\author{
Sabera Suleman and Tehmina Nazar \\ audacious_lass@hotmail.com \\ SZABIST \\ Karachi, Pakistan
}

\begin{abstract}
The dynamic times we are living in may be one of the most fascinating times to study mobile phone purchasing motives. There is not enough data available on the salient factors which affect the decision making process; usage and brand loyalty in mobile phone consumers belonging to different age groups. Therefore, this study addresses this subject by using the Models of Wheel of Consumer Analysis and Consumer Decision Making Process to evaluate two distinct age groups: 1835 years and 36-50 years. It further evaluates effect of marketing strategies on consumers of both age groups, based on a popular brand of Nokia.

Findings of this study show that younger consumers, aged 18-35 years, are comparatively more affective and more inclined towards technologically advanced mobile phones, whereas, the older consumers aged 36-50 years are more cognitive. Both the age groups are highly involved in the purchase decision of mobile phones. Word of mouth, mobile phone dealers' websites and advertisements play the most powerful role in influencing their purchase decision.

The final part of the study on behavior towards Nokia reveals the brand's unique selling points across both age groups are durability and quality. Majority is not satisfied with its pricing strategy and need more features at lower prices. However, older age group shows higher level of brand loyalty for Nokia.
\end{abstract}

Keywords: Consumer behavior, mobile phones, Wheel of Consumer Analysis, Consumer Decision Making Process, brand loyalty

\section{INTRODUCTION}

\subsection{Background}

A latest study conducted by Nokia pointed out that the people in Pakistan prefer style of mobile phones to the need of being connected. The study shows that the new devices combined with an attractive fold design with quick cover keys is bringing out substance to style, which is more acceptable in Pakistan as compared to other markets in the region of Asia and Asia Pacific. The study said that for innovation-conscious users, such mobile phones should be offered which have intelligent and entertaining multimedia functionality in an easy to use, ultra slim package [1].

\subsection{Research Objectives}

This study is aimed at finding out the differences of several aspects of consumer behavior in two broad age groups: $18-35$ years old and 36-50 years old. The main objective of the research was to find out: the salient factors affecting the two different age groups in the purchase and usage of the mobile phones by using the Wheel of Consumer Analysis; the decision making process of the two different age groups which leads to the selection and purchase of the mobile phone purchase and usage, level of brand loyalty exists in the two different age segments for Nokia and evaluate how effectively the marketing strategies of Nokia meet the needs of today's consumers of the two different age groups.

\subsection{Research Methodology}

Two Focus Group discussions were conducted with two broad age segments, each group consisting of 6 respondents. The sample size determined by the researcher for the survey was 100 . Out of the 100 respondents, 50 respondents were selected for each age group. Judgmental Sampling had been used for this study, which is one of the types of Non Probability Sampling. Survey was conducted based on 2 detailed structured questionnaires, aiming at Nokia users and Non-Nokia users. Unstructured interviews with the Brand Managers of United Mobile and Mobile Zone were conducted.

\section{LITERATURE REVIEW}

\subsection{Introduction to Consumer Behavior}

Consumer behavior, as a discipline, originated in the mid-to late 1960s. Many of the early theories were based on the economics theory presuming that consumers act rationally to maximize satisfaction in their purchase of goods and services [2].

As a field, consumer behavior represents the intellectual meeting ground for investigators from economics, marketing, applied psychology, sociology,

Journal of Independent Studies and Research (JISR) - Management and Social Sciences \& Economics

Volume 6, Number 2, July 2008 
anthropology, philosophy, family sciences, and related disciplines. Those researchers who find consumer behavior synonymous with marketing define consumer behavior as "the scientific study of consumer actions in the marketplace” [3]. However, some view consumer behavior as independent of marketing or any particular discipline. Jacoby (1976), for example, defined consumer behavior as "the acquisition, consumption and disposition of goods, services, time and ideas by decision-making units [4].

\subsection{Wheel of Consumer Analysis}

Wheel of Consumer Analysis was created by J. Paul Peter and Jerry C. Olson (1994). Marketers can analyze consumer behavior situation according to the following three elements, using the Wheel of Consumer Analysis:

a) the environment, which refers to all the physical and social characteristics of the consumers' external worlds, on both macro and micro level

b) behavior, which deals with what customers actually do

c) affect/cognition, where affect concerns feelings, while cognition involves thinking [5]

\subsection{Decision Making Process and Purchase Decision}

Decades ago, John Dewey (1910) conceptualized decision-process behavior as problem solving - thoughtful, reasoned action focused on need satisfaction [6]. Whereas, modern researchers are of the thought that decision making process is a rational and systematic process, which occurs before the actual behavior. Most of the consumer behavior textbooks refer to the elements of the consumer decision process in terms of the traditional five step classification, i.e. the cognitive decision sequence of problem recognition/pre-search stage, information search, alternative evaluation, choice, outcome evaluation [7], [8], [9], [10]. Some prefer to add one or more additional stages to place importance on certain phenomena/activities such as the inclusion of blocking mechanisms, the disposal of the unconsumed product or its remains [11].

\subsection{Brand Loyalty}

Brand loyalty is the ultimate desired outcome of consumer learning [12]. According to Rawly and Dawes (1999), brand loyalty is the likelihood of positive attitudes and behaviors of consumers towards a particular brand; this could amount to repeat purchase and positive word of mouth. They also stated that a loyal customer base is an asset for a company and it reduces the need for seeking new customers [13]. Looking from the point of view of a company, the strongest measure of brand value is the loyalty; a company produces among customers [14].

\section{ANALYSES AND INTERPRETATION OF THE SURVEY}

\subsection{Wheel of Consumer Analysis}

\section{Affect and cognition}

According to the respondents from both the age groups, the main factor, which motivates them to purchase a mobile phone, is to use it as a means of communication. Calling and SMS are the first and second priorities for both the age groups, respectively. $14 \%$ of the older respondents use mobile phones for the purpose of making calls only and they don't use other functions at all, while the preference for other features is low for the younger age segment, those features are used by this age group nonetheless.

A high percentage of both age groups go through the price/feature comparison (cognitive), though the percentage is higher for the older age group. Therefore, younger age group is relatively more affective towards the purchase of mobile phones, as $24 \%$ of them make purchase more on the basis of style, design and colors rather, than the features of the phone sets.

\section{Behavior}

Majority of both the age groups (over $78 \%$ respondents) plan their purchase before actually buying the mobile phones. More than $60 \%$ of the respondents from both the age groups personally make the purchase of mobile phones and more than $45 \%$ of the respondents personally look for information and make the final choice related to mobile phone sets they intend to purchase.

\section{Environment}

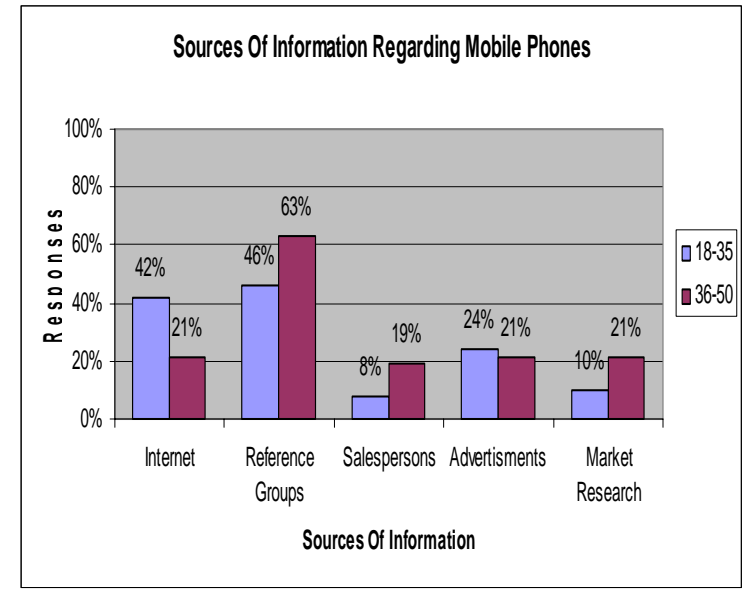

Figure 1

Journal of Independent Studies and Research (JISR) - Management and Social Sciences \& Economics Volume 6, Number 2, July 2008 
While $46 \%$ in the younger age group rely on reference groups, a higher $63 \%$ of older segment look towards them for source of information in purchase of mobile phones. Internet plays the second biggest part in influencing the younger age group, as they are more inclined towards Internet. Further, the situational factors (in this case the shop's environment and salespeople) play a minimal amount of role in influencing the purchasing behavior of both the age segments.

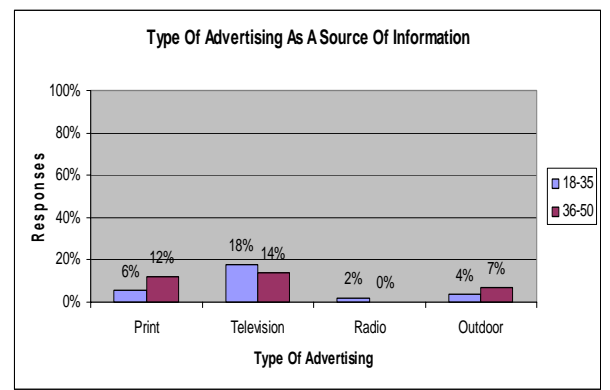

Figure 2

Only 24\% and 21\% respondents in the younger and older age segments consider advertising to be a key tool in providing information on mobile phones. Out of these, majority of both the age groups follow TV advertisements followed by print advertising, although it impacts the older age group greater.

More than half of the respondents in both the age groups are influenced by the medium price range of mobile phones (Rs. 5,000-Rs. 10,000).

Interestingly, more than $70 \%$ of both the age groups deny having any influence of celebrity endorsement on their purchasing decision.

As more than $58 \%$ of the younger respondents follow advancements in technology, $40 \%$ of the older respondents have switched their mobile phones for the sake of getting new technological features. Bluetooth is by far the most popular technology between both the age groups, which motivated them to give up their mobile phones. Camera is the second most in-fashion technology after Bluetooth, among the younger age group. In case of older age group; the second-most preferred technologies are Internet and Radio.

Most of the respondents from both the age groups claim to have no influence of salespeople on their buying behavior. Comparatively, the younger age group is more influenced (44\%) than the older age group (30\%). On the contrary, more of the older respondents seek salespeople's opinions regarding the mobile phones than the younger ones.
Among the Reference Groups, friends play the most influencing role in the buying decision of both the age segments (52\% and 54\% respectively). Colleagues are the second most influential factor in their buying decision on mobile phones.

\subsection{Consumer Decision Making Process Model}

\section{Problem recognition}

The problem and need for mobile phones arises when the consumers need to communicate or keep in touch with people, especially their family members, when they are away from home. This is true for both the age groups.

\section{Information search}

The older respondents are more involved into the mobile phone information search (62\%) than the younger respondents (46\%). Majority of the younger respondents look for the information regarding mobile phones from reference groups (46\%) and Internet (42\%); whereas, the older group relies mostly on their reference groups (63\%). Most of the older and younger consumers have a prior knowledge and information about the mobile phones at the point of purchase.

\section{Alternative evaluation}

Majority of both the age groups plan their purchase of mobile phones. They assess different alternatives, on the basis of their prices, features, design, quality, durability, etc., making a final decision or choice. Therefore, mobile phones can be considered as a high involvement product in Karachi.

\section{Purchase decision}

After evaluating the alternatives, both the groups make the final decision of their purchase. As compared to the younger age group, a higher percentage of the older respondents make their own decision by personally going through extensive information searching process. Younger group's decision is more inclined towards the appearance of the mobile phones, which is, the style, colors, shape, size, and design. Whereas, the older segment's decision is more on the basis of the features and value against the prices of the mobile phones.

\section{Purchase evaluation}

More than $70 \%$ of the respondents in both the age groups have not suffered from cognitive dissonance. 


\subsection{Brand Loyalty and Effectiveness of the Marketing Strategies of Nokia}

More than $50 \%$ of the older respondents have owned Nokia for more than 5 years as compared to more than $50 \%$ of the younger group owning Nokia since 2-5 years. This shows older group is more loyal towards Nokia, since majority of them haven't changed the brand since 5 years or more.

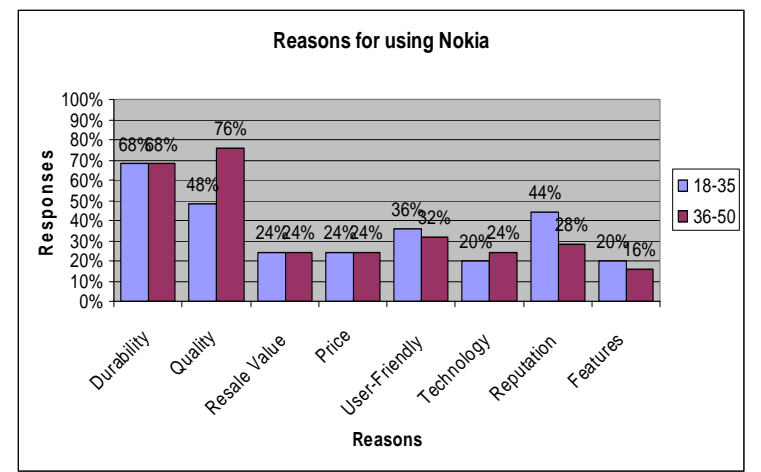

Figure 3

Word of Mouth has played a huge role in informing both the age groups about Nokia. Therefore, Word of Mouth is the strongest communication tool for Nokia. Advertisements of Nokia follow Word of Mouth in creating its awareness in both the age groups.

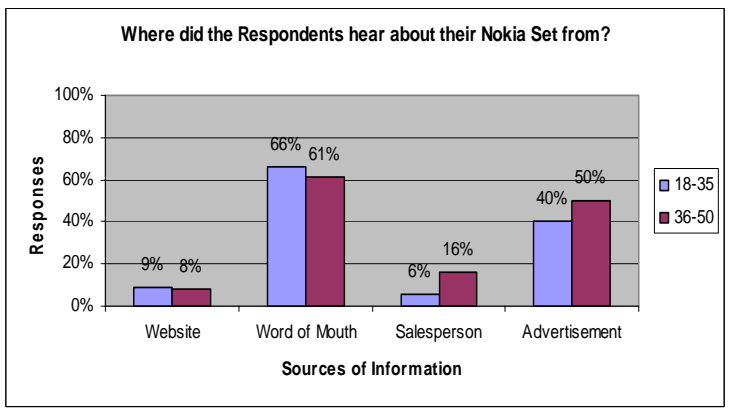

Figure 4

Durability of Nokia mobile phones is unique selling point for the younger Nokia users to own it. For the older group, it is the quality that matters the most. More than half of the older Nokia users are reluctant to switch Nokia as compared to less than half of the younger Nokia users. This again implies that the brand loyalty exists more in the older age groups than the younger segment.

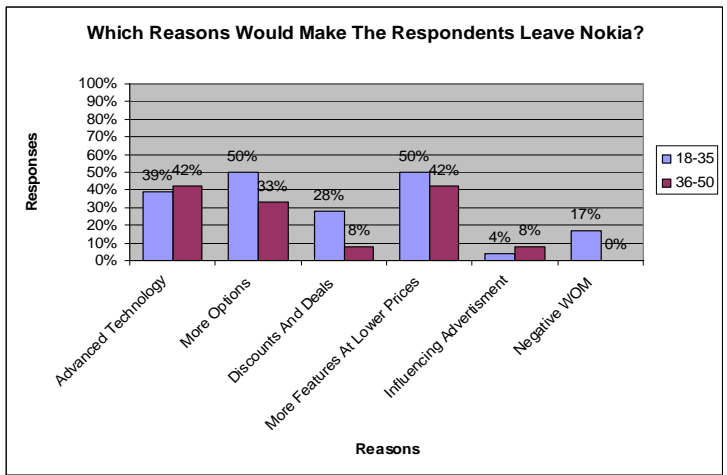

Figure 5

Those Nokia users who are willing to switch Nokia would do so primarily to get more options and features at lower prices in the younger age group and to get advanced technology and features at lower prices in the older segment.

$80 \%$ of the older Nokia users have not owned any other brand of cell phone than Nokia before. The percentage of the younger segment owning some other brand is higher (52\%), which shows less loyalty for Nokia in this age group.

Majority of Nokia users in both the age groups could not recall the current advertisement of Nokia appearing on Television, which shows Nokia's current promotional strategies have proven to be ineffective. However, comparatively a higher percentage of older respondents were able to recall Nokia's advertisement. This implies that Nokia's current promotional strategies are relatively ineffective towards the younger age group.

More than $70 \%$ of non-Nokia users have, in both age groups, switched from Nokia brand. The main reason for switching was to avail more features at lower prices from another brand in the younger age group.

\section{CONCLUSION AND RECOMMENDATIONS}

\subsection{Conclusion}

- Mobile phone consumers aged 36-50 are comparatively more cognitive and rational, who value features and worth of phone, while younger aged 18-35 prefers style and design. However, both the age groups prefer the basic features of mobile phones, i.e. calling and SMS. Though comparatively, technologically advanced features play a greater role in attracting the younger age group towards the mobile phone sets.

- Both the age groups plan their purchase and are highly involved in their purchase decision. The

Journal of Independent Studies and Research (JISR) - Management and Social Sciences \& Economics Volume 6, Number 2, July 2008 
situational factor, i.e. a visit to the mobile phone dealer, does not play much of a role in influencing their behavior, as most of them have already made their decision.

- Within the external environment for both age groups, word of mouth, mobile phone dealers' websites and advertisements play the most powerful role. Both the age groups consider medium price range, most suitable for mobile phones. Salespeople exert very little purchase influence for both age groups.

- The main USPs of Nokia across both the age groups is its durability and quality. Brand loyalty for Nokia is stronger across the older age segment.

- Respondents from both the age groups are not satisfied with the pricing strategy of Nokia. They want more features at lower prices. A vast majority in both age groups could not recall its TV ad.

\subsection{Recommendations}

- To be at par with other brands, Nokia needs to either reduce its price to match the features it is offering, or it should increase the number of features according to the price charged, especially the advanced technology, to retain its present customers and attract more from another brand across both the age groups.

- As Nokia is currently promoting through international advertisements, it would be most preferable for Nokia to get back to its local campaigns as people of Karachi relate to the endorsements, which give them a local feeling. Also, Nokia needs to increase the frequency of advertisements, both in the television and print medium.

- Nokia needs to persuade its dealers to display Nokia's phone sets more prominently and ostensibly than other brands, by offering them commission or discounts (trade promotion). It also needs to increase the frequency and quality of training provided to the salespeople of its main dealers.

\section{AREAS OF FURTHER RESEARCH}

This study only focused on one of the aspects of demographics, that is, the age groups. Further research on mobile phone purchasing behavior in Karachi can be done on the basis of income groups, educational level and employment status.

\section{REFERENCES}

[1] http://telecompk.net/2007/03/28/cell-phone-users-inpakistan-prefer-style-over-features/

[2] SCHIFFMAN, LG \& KANUK, LL, 2000, Consumer Behavior, 7th ed., London, Prentice Hall.

[3] Robertson, Thomas \& Kassarjian, Harold H. (1991), Handbook of Consumer Behavior, Englewood Cliffs, N J: Prentice-Hall.

[4] Jacoby, Jacob (1976), ACR Presidential Address 1975, In Beverlee B. Anderson (ed.), Advances in Consumer Research 3 (pp. 1-11), Ann Arbor, MI: Association for Consumer Research.

[5] Olson, J. C. \& Peter, J. P. (1994), Understanding Consumer Behavior, Burr Ridge, IL: Richard D. Irwin, Inc.

[6] Dewey, J. (1910). How We Think, Boston: D. C. Heath.

[7] SCHIFFMAN, LG \& KANUK, LL. 1994, Consumer Behavior, $5^{\text {th }}$ ed., London, Prentice Hall.

[8] SOLOMON, MR. 1996, Consumer Behavior, Buying, Having and Being, 3rd ed., London, Prentice Hall.

[9] DU PLESSIS, PJ \& ROUSSEAU, GG \& BLEM, NH. 1991, Consumer Behavior, A South African Perspective, Pretoria. Sigma.

[10]FOXALL, GR. 1983, Consumer Choice, London. MacMillan.

[11]ENGEL, JF, BLACKWELL, RD \& MINIARD, PW. 1995, Consumer Behavior, International ed. Florida. Dryden.

[12] Schiffman, L. G. and Kanuk, L. L. (2004), Consumer Behavior, Eight Edition, Prentice-Hall of India.

[13] Rowley J. and Dawes J. (1999), Customer Loyalty A Relevant Concept for Libraries? Journal of Library Management, 20, 6, 345-351.

[14] Aaker, David A. (1991), Managing Brand Equity, The Free Press Simon \& Schuster Inc: New York. 